\title{
One century of the macromolecule concept
}

\author{
Maria Isabel Felisberti ${ }^{*}$ \\ ${ }^{1}$ Instituto de Química, Universidade Estadual de Campinas - UNICAMP, Campinas, SP, Brasil \\ *misabel@unicamp.br
}

How to cite: Felisberti, M. I. (2020). One century of the macromolecule concept. Polímeros: Ciência e Tecnologia, 30(1), e2020000. https://doi.org/10.1590/0104-1428.03001

Hermann Staudinger (1881-1965) was a German $\mathrm{PhD}$ in Organic Chemistry, who proposed that natural rubber was a covalently bound polymer with high molar mass, contradicting the accepted hypothesis of colloidal aggregation of small molecules ${ }^{[1]}$. He started his carrier as professor of organic chemistry at the Technical University of Karlsruhe, Germany, followed by the Eigenössische Technische Hochschule (ETH) in Zurich, Swiss, and the Albert Ludwigs University in Freiburg, Germany, where he became director of the chemistry department. Parallel to the research in organic chemistry, he was interested in physiology of the active natural compounds ${ }^{[1]}$. Staudinger was a leading organic chemist ${ }^{[2]}$. However, in 1920s, he left the classic organic chemistry to dedicate his life to the emerging and challenging polymer science. He faced strong opposition from colleagues, who did not understand why he changed the interesting field of the small and defined molecules to poorly defined molecules, such as rubber and synthetic polymers, at that time denominated as "grease chemistry". However, he was persistent and able to provide direct and indirect evidences of the macromolecular nature of both natural and synthetic compounds, which at that time was thought to be quite different ${ }^{[1]}$. His wife Magda Staudinger was a plant physiologist, with relevant contributions to Macromolecular Science, that encouraged Staudinger ideas about the importance of macromolecules for Biochemistry and Biology ${ }^{[1,2]}$. According to Staudinger, synthetic polymers are models to understand biopolymers and more complex biosystems. He contributed to significant and fundamental advances in macromolecular chemistry; prepared and characterized a variety of macromolecules, including synthetic polymers, biopolymers and modified biopolymers. He demonstrated that synthetic polymers could be formed into fibers, which was thought to be possible just with biopolymers. His studies on crystallization provided evidences that small segments of the polymer chains constitute the unit cell of a crystalline polymer. From Staudinger law, which correlates the viscosity of a polymer solution with the molar mass, viscosimetry became a powerful technique for polymer characterization, still used in academia and industry. Staudinger first investigated the morphology of macromolecules by using transmission electron microscopy ${ }^{[2]}$. In 1940, Staudinger founded the Institut für Makromolekulare Chemie (Institute for Macromolecular Chemistry) at the Albert-Ludwigs Universität Freiburg (University of Freiburg), the first European center for inter and multidisciplinary polymer research. In 1941, he became director of the Institute of the Macromolecular Chemistry, which became a Government Research Laboratory. In 1947, he founded the journal Die Makromolekulare Chemie, today Macromolecular Chemistry and Physics. In 1953, Hermann Staudinger was awarded Nobel Prize for Chemistry for the concept of macromolecules and his efforts to stablish the Macromolecular Science ${ }^{[1]}$. In his Nobel lecture, Hermann Staudinger stated

The macromolecular compounds include the most important substances occurring in nature such as proteins, enzymes, the nucleic acids, besides the polysaccharides such as cellulose, starch and pectins, as well as rubber, and lastly the large number of new, fully synthetic plastics and artificial fibres. Macromolecular chemistry is very important both for technology and for biology $y^{[3: 397]}$.

\section{References}

1. Cantow, H.-J., \& Mülhaupt, R. (2013). Hermann staudinger and polymer research in freiburg. In V. Percec (Ed.), Hierarchical macromolecular structures: 60 years after the staudinger Nobel Prize I. Advances in polymer science (Vol. 261, pp. 21-38). Cham, Switzerland: Springer International Publishing. http:// dx.doi.org/10.1007/12_2013_257

2. American Chemical Society. (1999). Hermann Staudinger and the Foundation of Polymer Science. International Historic Chemical Landmark. Washington: ACS. Retrieved in 2020, March 26, from http://www.acs.org/content/acs/en/education/ whatischemistry/landmarks/staudingerpolymerscience.html

3. Staudinger, H. (1953). Macromolecular chemistry (pp. 397-419). Stockholm: The Nobel Prize. Retrieved in 2020, March 26, 